QUADERNS DE FILOSOFIA VOL. III NÚM. 2 (20I6): I I-36

ISSN: 234I-I4I 4 eISSN: 234I-3042 DOI: IO.7203/QFIA.3.I.72I 8

Héctor Arévalo Benito

Universidad Técnica Particular de Loja (Ecuador)

\title{
La temprana formación literaria del joven José Gaos en Valencia (I9I5-I9I9)
}

Recibido: 28/10/15. Aceptado: 30/1/16

Resumen: Nuestra intención en este texto es investigar acerca de los primeros años de formación del pensamiento de José Gaos (1900-1969); así pues, no parece ser demasiado erróneo pensar que aquél, hacia 1915 no era, aún, puramente "filosófico": la Filosofía representaba parte de su formación, cumpliendo el mismo papel —eso sí: básico y fundamental— que desempeñó la Literatura. El primer auténtico encuentro con la Filosofía se daría antes de su llegada a Valencia, en ese mismo año de 1915; pero ese también es el año en que Gaos recibirá una sólida formación estético-literaria a través de prensa y revistas filosóficas, especialmente en el grupo que conformó junto con Max Aub, José Medina Echeverría y su hermano Carlos Gaos.

\begin{abstract}
This paper investigates in detail about the early years of José Gaos (19001969) and his education in philosophy and literature. Therefore, we know that their studies (academic or not) were not purely "philosophical" in 1915. Literature and philosophy played in Gaos an equally important role. The first real encounter with philosophy happens before he comes to Valencia in 1915; but in this year Gaos also receives a strong education, in aesthetic and literary, through press and philosophical journals, and especially within the group formed with Max Aub, José Medina Echeverría and his brother Carlos Gaos.
\end{abstract}

Palabras clave: José Gaos, literatura, juventud, formación, Valencia.

Keywords: José Gaos, literature, youth, education, Valencia. 
E

N ESTE BREVE ESCRITO, trataremos la cuestión de la formación literaria de José Gaos (1900-1969) entre 1915 — la fecha de su llegada a Valencia-, y el año de 1919 — fin de la etapa preuniversitaria_- Sea como fuere, debemos atender a cuál había sido, antes de 1915, su trayectoria anterior completa en lo que respecta a la formación literaria y filosófica, y por ello debemos continuar explicando que el Gaos niño (precoz lector de Cervantes, en 1909 o 191 1), que proveniente de Gijón llegó en 1911 a Oviedo, en 1915 ya había cursado cuatro años académicos de su bachillerato en un centro dominico ovetense, ${ }^{2}$ durante los cuales (de primero a cuarto de bachillerato: 1911-1915) se ha encontrado en su periplo de formación y autoformación, primero con la Literatura (con ésta se encuentra durante el bachillerato, en 1914; a causa tanto de la "Preceptiva Literaria" ${ }^{3}$ como de la experiencia decisiva, pero tempranamente

\footnotetext{
${ }^{1}$ Gaos, J. I999, "Carta 1", en Gaos, J. 1999, O. C., t. XIX, Epistolario y Papeles Privados, México: UNAM.

${ }^{2}$ La historia del centro se remite a la fundación del Convento de los dominicos (1518) por
} el P. Pablo de León. Durante los siglos pasados, muchos religiosos de este Convento enseñaron teología en la Universidad, y algunos filosofía en las cátedras de la Orden en Cangas de Tineo e Infiesto (dentro del convento también hubo cátedras). En 1835, los edificios conventuales pasaron a ser Hospital; en 1851, estos edificios fueron dados a la diócesis para convertirlos en seminarios. Desde 1895, se restauró la Orden dominica en el convento, y se puso por esos años un colegio que funcionó hasta 1922. Tras esta fecha, volvió a ser seminario. Tras la guerra civil quedo dañado, y en 1946 se levantó un Colegio de Segunda Enseñanza. Cfr. http://www.dominicosoviedo.com/historia.asp?v=5 [Consultado: 1.9.10]. Según la información de la web del propio centro, vemos que antes de 1946 la orden dominica destinó el lugar durante poco más de un par de décadas a ser estrictamente Colegio.

${ }^{3}$ Con el Plan de Estudios (20 de julio de 1900) de A. García Alix el bachillerato constaba de seis cursos. De la asignatura de "Preceptiva Literaria" se decía que era: "de carácter práctico (...) [y que] pondrá a nuestros escolares en condiciones de usar con corrección el lenguaje”. Según la ley, la "Preceptiva Literaria" se tenía que impartir en dos de los seis cursos del Bachillerato. Al proponer la Ley Alix un único bachillerato — unificado-, suponemos que la asignatura de "Preceptiva Literaria" tenía como función asegurarse desde el Ministerio que los alumnos con formación científico-técnica tuvieran asimismo una excelente capacidad de expresión y comprensión - tanto lingüística como literaria. La creación de un único Bachillerato, fue debido a la imposibilidad — por razones económicas — de mantener dos bachilleratos distintos (uno orientado a las letras y otro a las ciencias). Gaos hasta entonces no había escrito nada — solo cartas, exámenes, apuntes...—, y sin embargo, cuando empezó a escribir (tarea práctica propia de esta asignatura), aquél lo hizo en verso y en prosa. Y no solo es una forma de hablar: el joven Gaos tomó como modelos estéticos de sus textos la narración de Amés, príncipe de Egipto - la cual leyó en aquellos días en formato de "tragedia en prosa y verso, en cinco actos", seguramente de la Biblia, así como algunas obras maestras de la literatura, comenzando por Shakespeare. Gaos, J. 1982, "Confesiones Profesionales [1953]", en O. C., t. XVII, Confesiones Profesionales. Aforística, México: UNAM, 53.

El profesor que tuvo Gaos en esta materia fue Augusto Díez Carbonell: Díez Carbonell era un profesor de Literatura el cual había publicado — precisamente, en 1915-, "Apuntes para un manual de Filología castellana" (133 pp.); en 1917 publicó "Lengua y Literatura Españolas" (406 pp.) y, ya en 1923, "Teoría elemental de la Literatura". Asimismo, escribió un texto de 
interrumpida, de la creación de la Revista Cultura $^{4}$ ); posteriormente, decimos, Gaos se ha aproximado a la filosofía (gracias a la doble lectura de Balmes, a fines de primavera y el verano de 1915 en Luanco, y tras las aproximaciones fallidas al positivismo y a Tomás de Aquino ${ }^{5}$ ). Sobre su formación filosófica, en definitiva, conocemos suficientes datos útiles para formarnos una idea de sus intereses y estudios filosóficos; ahora bien, otra cosa bien diferente es lo referido a la formación literaria del joven Gaos, la cual no conocemos con tanto

\begin{abstract}
"Preceptiva Literaria (Los géneros de la Literatura Española)" (en 1932, 118 pp.). Otras obras: "Primer Grado de Lengua Española”, “Tercer grado de Lengua Española” (1934, 84 y 71 pp. respectivamente.), "Lengua Española y Literatura. (Cuarto Año [de Bachillerato]. Gramática)", (1935, 149 pp.). Por otro lado, hay que decir que el 1 de enero de 1940 Díez Carbonell, sin embargo, figuraba como Catedrático de Instituto. B.O.E. 1 de marzo 1940. Cfr. http://www. filosofia.org/hem/dep/boe/194003.htm. [Consulta: 16.11.2010].
\end{abstract}

Bajo nuestra interpretación, la "Preceptiva Literaria" debió de ser crucial para muchos filósofos de aquella época, y creemos que no se trata de una exageración nuestra: la ley que planteaba la creación de esta asignatura parece que surtió el efecto buscado, pues tuvo un fuerte impacto no solo en Gaos, sino también en algunos otros de su generación. Cabe señalar, pues, que "Preceptiva Literaria" causó gran impresión en el P. Díez-Alegría (1911-2010), pues "le marcó una huella e inclinación hacia las letras" en sus estudios de $4^{\circ}$ y $5^{\circ}$ de Bachillerato (1923-1925) y que siempre perduró. Dicho sea de paso, el profesor que tuvo Díez-Alegría —en Gijón; no en Oviedo - fue el poeta Gerardo Diego. Cfr. Delgado de la Rosa, J. A. 20 io, Libertad de Conciencia y Derechos Humanos. Vida y Pensamiento de José María Díez-Alegría, Madrid: Universidad Carlos III de Madrid, 31.

${ }^{4}$ Pero, y al hilo de la "Preceptiva Literaria", hay que decir que muy pronto toda la escritura que pudo acometer Gaos con la práctica de la asignatura de "Preceptiva Literaria" le resultaría insuficiente; fue entonces cuando se le ocurrió fundar una revista escolar en el colegio ovetense dominico, con el fin de poder escribir amplia y generosamente y que, publicada, pudiera "circular por el Colegio". En esta Revista pretendía no solo escribir él, sino que Gaos también buscaba que escribiesen tanto sus compañeros como los Padres dominicos profesores; incluso quería que estos últimos le entregaran artículos que Gaos "copiaría" él mismo y publicaría en la Revista. Con esta estrategia, Gaos pretendía que la publicación pudiera abarcar todos los sectores de la cultura; es decir, Gaos quería que en ella hubiera: [...] poesías, cuentos, [...] críticas no solo literarias y de arte, sino hasta de toros, $[\ldots]$ artículos sobre [...] todas las asignaturas del bachillerato". GAOS, J. 2003, "[Gaos visto por sí mismo, 1942]”, en O. C., t. III, Ideas de la Filosofía (1938-1950), México: UNAM, 365. Quienes conocen más sobre esta Revista, sabrán de la historia infructuosa de la misma, así de cómo en ella intentó Gaos incluir la materia de "filosofía", sin ningún éxito. Cfr. Ibid. También: GaOs, J. I982, "Confesiones Profesionales [1953]", en O. C., t. XVII... 53.

${ }^{5}$ El primer encuentro con la filosofía — precisamente, al hilo de la Revista Cultura, y del intento de escribir en ella sobre "Filosofía" —, fue en un muy joven Gaos, y a través de "[...] $P_{s i-}$ cología, Lógica y Ética de [José] Verdes Montenegro. Los hojeé, leí en ellos, pero no los entendía nada bien y, sobre todo, no me interesaron". (Cfr. Gaos, J. 1982, "Confesiones Profesionales [1953]”, O. C., t. XVII... 54). El segundo encontronazo fue con Santo Tomás: un dominico y profesor de trigonometría le prestó un libro panegírico, el cual, le "aburrió y sobre todo no me pareció prometedor, al menos con la urgencia del caso, e hice lo posible por zafarme de la continuación [de su lectura]". Cfr. GAOs, J. 2003, "[Gaos visto por sí mismo, 1942]”, O. C., t. III... 366. El tercero fue la famosa lectura de las observaciones balmesianas sobre la historia de la filosofía, relato bien conocido — a pesar de lo cual, algunas palabras decimos en este artículo-. 
detalle, razón por la que pretendemos aquí recabar algunas informaciones relevantes, de cara a poder plantear la posible influencia de su cultura literaria adolescente y juvenil en su concepción filosófica posterior —influencia literaria, la cual, por ejemplo, daría buena muestra su interés en el curso de 1935/36 por enseñar conjuntamente literatura y filosofía, ${ }^{6}$ así como en su posterior formulación, hacia mitad de los años 40, momento en el que Gaos plantea en qué consiste, según su criterio, el pensamiento de lengua española. ${ }^{7}$

Llegados a este punto, debemos continuar atendiendo al giro radical que acaece en la vida de Gaos con su cambio de vida: pues aquél se traslada desde Asturias a Valencia a primeros de octubre de $1915,{ }^{8}$ lugar de residencia de sus

${ }^{6}$ Así pues, en este año en la nueva y flamante facultad madrileña de Filosofía (además de Introducción a la filosofía), Gaos impartiría un nuevo curso que denominó como "Teoría y Didáctica de las Ciencias del Espíritu”. Esta asignatura la dividió en dos partes. La primera parte, denominada "la filosofía y su didáctica"; y, la segunda, "las letras y su didáctica". En esta segunda parte — según testimonio del P. Mindán—, "despertó singular interés”, pues trataba sobre la literatura y su enseñanza. De esta manera, en el apartado de "Las letras y su didáctica" de la asignatura de "Teoría y Didáctica de las Ciencias del Espíritu", Gaos "explicaba la teoría" y hablaba sobre "la esencia de la literatura", y Fernández Montesinos, por su parte, se ocupaba de "corroborar la doctrina expuesta con la lectura y comentario de trozos literarios de escritores y poetas conocidos". Cfr. Mindán, M. 200I, "El magisterio de José Gaos en España”, en En torno a José Gaos, T. Rodríguez de Lecea (ed.), Valencia: Institució Alfons el Magnànim-Diputació de València. Especialmente, 65 y 66. También puede verse: MorA, J. L. 20 I4, "María Zambrano: Cervantes y la reforma del entendimiento español", eHumanista, vol 3, 661-74 [Volumen dedicado a Cervantes. http://www.ehumanista.ucsb.edu/Cervantes/volume\%203/pdf/ehumcerv3. mora.pdf (Consulta: 2.1.2015)].

${ }^{7}$ Así pues, para Gaos, si tomamos "la totalidad" del pensamiento hispanoamericano desde la edad moderna hasta la contemporánea encontraremos como omnipresente dicha vertiente literaria, ya que — afirma — nuestro pensamiento, "en todos los casos, es bella literatura — de la más subida calidad”: "Sus 'nombres centrales', Sarmiento, Montalvo, Martí, Rodó, Unamuno, Ortega, son los de los grandes prosistas de lengua española desde los siglos de oro. Pero cuántos nombres circundantes y periféricos que añadir. Nombres de pensadores escritores". Cfr. GaOs, J. 1993, O. C., t. V, El pensamiento hispanoamericano. Antología del pensamiento de lengua española en la edad contemporánea, México: UNAM, 96.

Creemos que, además, es necesario señalar que en el "pensamiento hispanoamericano", para Gaos, e incluso desde los niveles más "ínfimos" de nuestro pensar, hay siempre un "pensamiento didáctico" y expresado con "corrección", al tiempo que - afirma - nuestro pensamiento de lengua española es un "pensamiento característicamente estético" por la "calidad y excelencia" que se da en su expresión, debido a: "[1] sus formas de expresión y comunicación; [2] sus formas verbales, literarias, escritas y orales; [3] sus formas en la acepción de los géneros literarios y de expresión y comunicación, en general, que usa, que prefiere, y [4] en la acepción del estilo" Cfr. Ibid., 59.

${ }^{8}$ GaOs, J. 2003, "[Gaos visto por sí mismo, 1942]", O. C., t. III... 366. En el texto de esta obra, parece que figura el número "10" de octubre. Sin embargo, en GaOs, J. i982, "Confesiones Profesionales [1953]", O. C., t. XVII... 55, aparece escrito del siguiente modo: "1o. de octubre", lo cual se refiera seguramente al primer día de octubre. Sea como fuere, se trasladó a primeros de octubre. 
padres y hermanos. ${ }^{9}$ Su padre trabaja allí en calidad de "jurista distinguido como conocedor del Derecho Hipotecario". ${ }^{10}$ De esta manera, es conocido que Gaos vivirá en Valencia desde octubre de 1915 — salvo algunas interrupciones ${ }^{11}$ — hasta su marcha a Madrid en 1921. Sabemos, asimismo, que al joven Pepe le costará adaptarse a la nueva realidad familiar, pues es consciente de que al haber vivido la pubertad con sus abuelos, no alcanzará nunca del todo el grado de filiación que hubiera deseado tener con su padre, ${ }^{12}$ así como — quizá- con el resto de sus familiares.

Así pues, sabemos que José Gaos cursará los últimos años del bachillerato en Valencia —este extremo nos lo confirman Manuel Mindán ${ }^{13}$ y Fernando Salmerón ${ }^{14}$ —, estudiando los últimos cursos de bachiller en las Escuelas Pías de Valencia, una institución que en aquellos años estaba adscrita al Instituto General y Técnico de Valencia. ${ }^{15}$ Hay que resaltar que durante esta etapa en Valencia no solo son importantes sus estudios de enseñanza secundaria, sino también el hecho de que Gaos entablará relación con dos compañeros de clase, José Medina Echevarría y Max Aub, con los cuales mantendrá firmes relaciones de amistad durante su vida en Valencia. Así, y junto con su hermano Carlos, Aub y Medina, los cuatro, conformarán un curioso grupo juvenil que lleva a cabo numerosas lecturas, escribe poesía y teatro y lee a menudo periódicos españoles y franceses — como se verá más abajo. Desde un punto de vista relacionado con su vida privada, podemos también añadir que, incluso, de estos años Gaos nos mencionará también un platónico amor de juventud, Cristina Plá, hija del gran pintor Cecilio Plá y Gallardo (1860-1934), a la cual conoció en Valencia. ${ }^{16}$ Pero esto último, y por desconocer más datos sobre este amor, solo cae en nuestro escrito en el lado de la anécdota. Pasemos ahora, pues, a conocer más detalles sobre su juvenil y apasionada aproximación a la literatura.

${ }^{9}$ Carlos y María vivían en Orihuela con sus padres desde que éstos se trasladaron. Abellán, J. L. 200I, "Los Gaos: una saga familiar eminente", en En torno a José Gaos, T. RodríGuez De LeceA (ed.), Valencia: Institució Alfons el Magnànim-Diputació de València, 220. Cuando Gaos llega a Valencia, hay nuevos hermanos en la familia (Alejandro, Ángel e Ignacio) los cuales no había visto nacer.

${ }^{10}$ Gaos, J. i 982, "Confesiones Profesionales [1953]", O. C., t. XVII... 55.

${ }^{11}$ Salmerón, F., "Los escritos españoles de José Gaos"... 307. Desconocemos a cuáles interrupciones se refiere Salmerón.

${ }^{12} \mathrm{Y}$ su padre con él. Al respecto, dirá Gaos: "no me comporté siempre como él quisiera" (Cursiva de Gaos). Gaos, J. I982, "Confesiones Profesionales [1953]", O. C., t. XVII... 84.

${ }^{13}$ Mindán, M. 200I, "El magisterio de José Gaos en España”... 57.

${ }^{14}$ Salmerón, F. 2000, Escritos sobre José Gaos, México: El Colegio de México, 307.

15 Ibid.

${ }^{16}$ El mismo Gaos dice de sí mismo que "se trataba de un chiquillo", si bien sabemos que fue en Valencia donde conoció a este amor de juventud. Cfr. Gaos, J. I999, Carta 5 (Domingo de Ramos [20]. 4. [1924]), en O. C., t. XIX, Epistolario y Papeles Privados, México: UNAM, 51. 


\section{DECEPCIONES FILOSÓfICAS, PERSEVERANCIA Y PASIONES LITERARIAS}

En definitiva, bien es cierto que podemos afirmar que a principios de octubre de 1915 tuvo lugar el reencuentro con el núcleo familiar valenciano: llega a Valencia un Gaos ya iniciado en los terrenos literario y filosófico, pero que - en nuestra opinión — se va a completar su formación en toda su extensión durante estos años valencianos, especialmente, en el aspecto literario. Y, al tiempo, creemos que hacia este último ámbito se orientará Gaos por una razón de ocio y tiempo libre: así, su continuación del bachillerato $\left(5^{\circ}\right.$ y $6^{\circ}$ curso) se prolongará al menos hasta fecha posterior al verano de 1918. Esto quiere decir que entre estos tres ańos académicos (1915/1916; 1916/1917 y 1917/1918) aprobará los dos cursos académicos que le restaban por hacer ${ }^{17}$ (en el verano de 1918, sabemos que aún no era Bachiller). Esto quiere decir, que probablemente, el resto del tiempo lo esté dedicando a los quehaceres propios de un adolescente, sí, pero también a la lectura, escritura y apreciación de obras estéticas y literarias —además de ampliar, de un modo u otro, su pasión recién adquirida: la filosofía.

Sin embargo, y a pesar de la (ya famosa) relectura del texto de Balmes en la casa familiar de los abuelos, en aquel verano de $1915,{ }^{18}$ debemos constatar, para comenzar, que el interés de Gaos por la filosofía parece que no se vio potenciado en sus estudios finales de bachillerato. No tuvo buenos profesores de filosofía en estos años. Tal y como afirma Mindán, Gaos "no guardaba buen recuerdo de los profesores del instituto al menos de los [que enseñaban] las asignaturas que más le interesaban". ${ }^{19}$ El propio testimonio de Gaos es muy negativo. En Confesiones Profesionales nos describe a sus profesores de filosofía

Este extremo nos lo confirma Aub: "Antes del año 20, íbamos a la playa de las Arenas a discutir, a veces, con Cecilio Plá, pintor excelente (...) Nos atraían mucho más Pepita y Cristina, sus hijas (...) Cristina, dulce pulpa, suave de color albaricoqueado, con ojos claros, le voló los sesos a Pepe". (Pepe es José Gaos). Aub, M. 200 i, "José Gaos", en Cuerpos Presentes, Valencia: Fundación Max Aub, 217.

${ }^{17}$ Según Alberto Espinosa, Gaos comenzaría a estudiar "Quinto Curso" en las Escuelas Pías, entre 1915 y 1916, y en "1917" (solo ofrece el año, pero no a qué curso pertenece), estudiaría en el Instituto de Segunda Enseñanza de Valencia. EspinosA, A. I999, "Cronología y bibliografía de José Gaos”, en Homenaje a José Gaos, AA.VV., México: FCE/La Gaceta del Fondo de Cultura Económica, 58.

Es posible que Gaos repitiese Sexto curso, cursándolo la primera vez en el Colegio de las Escuelas Pías, y la segunda en el Instituto de Enseñanza de Valencia. El hecho de que el propio Gaos afirme que leyó el Quijote por segunda vez en el verano de 1918, siendo "por entonces bachiller, o algo menos" (Cfr. GAos, J. I999, "Carta 1", en O. C., t. XIX... 39), podría corroborar, seguramente, la repetición del último curso de Bachiller.

${ }^{18}$ GaOs, J. I982, "Confesiones Profesionales [1953]", O. C., t. XVII... 55.

${ }^{19}$ Mindán, M. 200I, “El magisterio de José Gaos en España”... 57. 
como de escasa valía. No obstante, Gaos siguió manteniendo el vivo interés por la filosofía nacido de la lectura de Balmes. Así, en este punto es interesante señalar que sabemos cuáles fueron los primeros profesores de filosofía que vio pasar por las aulas como alumno en las Escuelas Pías de Valencia. Pues si bien era cierto que estaba cursando oficialmente materias relacionadas con la filosofía, sin embargo, y al tiempo de estos estudios, Gaos también estaba formándose de manera autodidacta, y con amigos, sobre arte, literatura, poesía, teatro, es decir, configurando un universo estético propio que, con el tiempo, acabaría dando sus frutos en su concepción sobre el pensamiento hispanoamericano. Pero veamos, primero, cuáles eran esos profesores de filosofía que durante la educación secundaria, y a pesar de su nula formación, no le hicieron aborrecer de la filosofía para siempre, y que, quizá —y gracias a la paupérrima preparación filosófica de dichos profesores - fueron el detonante de su creciente interés y formación, entre 1915 y 1919, por la literatura.

El primer profesor que le impartió clases de filosofía durante sus estudios de bachillerato en Valencia fue el padre Manuel Mayor, el cual estaba "provisionalmente encargado de la Filosofía". Era

[...] profesor de Psicología y Lógica en las Escuelas Pías [si bien era] profesor propiamente de Literatura, [y el cual] se limitó a no hacerme aborrecible la filosofía ${ }^{20}$

Solo acerca del padre Mayor mostrará una opinión neutra — seguramente por el hecho de ser titular de Literatura, y no propiamente de Filosofía一, pues con relación al resto de profesores contamos con una fuerte crítica.

Así, el segundo profesor con el que cursaría también clases de filosofía fue el profesor Manuel Polo y Peyrolón (1846-1918). ${ }^{21}$ Afirma Gaos que era Polo un "político de extrema derecha, senador, novelista olvidado [...] y vejete

${ }^{20}$ GaOs, J. 1982, "Confesiones Profesionales [1953]", O. C., T. XVII... 75. Sobre Manuel Mayor no hay datos en Díaz Díaz, G. 1998, Hombres y Documentos de la Filosofía Española, t. V, M-N-Ñ, Madrid: Consejo Superior de Investigaciones Científicas/Centro de Estudios Históricos.

21 "D. Manuel Polo y Peyrolón (1846-1918). Catedrático de Psicología, Lógica y Ética, nacido en Cañete (Cuenca). Estudió derecho y filosofía y letras en Valencia y Madrid. En 1867 fue nombrado profesor auxiliar en la cátedra del Instituto de Valencia, y en 1868 ayudante de metafísica en la Universidad de Valencia. Obtuvo en 1870 la cátedra de Psicología, Lógica y Ética del Instituto de Teruel, trasladándose en 1879 al de Valencia. Polo, de "sólidas convicciones cristianas" y "buen pedagogo", fue un propagandista católico y tradicionalista que llegó a ser representante en el Congreso, siendo senador desde 1907. Fue condecorado por León XIII con la cruz Pro Ecclesia et Pontifice. Fue socio de mérito de la Sociedad de Amigos del País de Alicante y de la Real Academia de la Historia, así como comendador de Isabel la Católica. Escritor de novela 
cascarrabias" ${ }^{22}$ Pero del profesor Polo no recibió clase durante mucho tiempo, pues falleció al poco de empezar el curso que impartía de "Ética y Rudimentos de Derecho". 23

Con relación al profesor que lo sustituyó inmediatamente, el profesor auxiliar José Feo — y este es el tercero que Gaos tiene en Valencia—, podemos decir que Gaos no le tuvo ningún respeto; incluso llegó a escribir sobre él que

[...] era un gordo realmente feo, un abogado mediocre y un profesor de filosofía, no digo un filósofo, nulo $[\ldots]^{24}$

Gaos, asimismo, sentenció que al profesor Feo tanto él como sus compañeros no le hacían caso, más bien que le tomaron "a chacota", ${ }^{25}$ y que se limitaron "a no estudiar con él realmente una palabra [de filosofía] —a pesar de lo cual, aprobamos" ${ }^{26}$ Los profesores que estaba teniendo, pues, no eran, precisamente, la encarnación de la filosofía de Balmes —el autor que tanto le había impresionado, primero, durante el curso 1914/1915 en Asturias, y después, durante una detenida lectura veraniega en 1915, antes de su llegada a Valencia.

Un cuarto y último profesor con el que estudió Gaos en Valencia fue Pedro María López y Martínez (1861-1934). ${ }^{27}$ Sobre él tampoco tendrá buena opinión. López y Martínez también enseñaba "Metafísica" en la Universidad

"costumbrista", era un "impugnador del darwinismo" de raigambre tomista. Cfr. DíAz Díaz, G. 1998, Hombres y Documentos de la Filosofía Española, t. VI, O-R, Madrid: Consejo Superior de Investigaciones Científicas/Centro de Estudios Históricos, 489-90. Véase también: Proyecto de Filosofia en Español http://www.filosofia.org/ave/001/a005.htm [Consultado: 9.9.10]).

${ }^{22}$ Ibid.

${ }^{23}$ El joven Gaos afirma que falleció "apenas había empezado" la asignatura —op. cit., 75—. Así, si atendemos a lo que se dice de él en Proyecto Filosofía en Español, falleció en abril de 1918. Cfr. Proyecto de Filosofía en Español http://www.filosofia.org/ave/001/a005.htm [Consultado: 9.9.10]). La misma fecha - abril de 1918 - establece el texto (como día de fallecimiento de Peyrolón) de Gonzalo Díaz. Díaz Díaz, G. 1998, Hombres y Documentos de la Filosofía Española, t. VI, O-R... 490. En cualquier caso, ambas fuentes nos indican que Gaos aún en abril de 1918 estaba estudiando el Bachillerato.

Sobre el nombre de la asignatura que se impartía en quinto curso del Instituto, la denominación en realidad primigenia era la de "Ética y Sociología". NúŃEz Ruíz, D. 2006, "Reforma y modernización de la universidad espańola en el gozne de los siglos XIX y XX", Revista de Hispanismo Filosófico, 11: 115.

${ }^{24}$ GaOs, J. I982, "Confesiones Profesionales [1953]”, O. C., t. XVII... 75.

${ }^{25}$ La expresión que realmente usa Gaos en 1953 es "tomar a chacota", es decir "a broma". Ibid.

${ }^{26}$ Ibid. Sobre José Feo no aparecen datos en Díaz DíAz, G. I988, Hombres y Documentos de la Filosofía Española, t. III, E-G, Madrid: Consejo Superior de Investigaciones Científicas/Centro de Estudios Históricos.

${ }^{27}$ Licenciado en Filosofía (1883) y Derecho (1886), fue bibliotecario en Huesca antes de ganar en 1892 la cátedra de metafísica de la Universidad de la Habana. Allí enseñó —además de Metafísica - Historia de la Filosofía. A su vuelta a Espańa, primero enseñó en la Universidad 
de Valencia - lo cual no era sinónimo, para Gaos, de que fuera buen docente- . Sin embargo, sobre él pensaba que trabajaba como profesor de Metafísica, Lógica Fundamental y Teoría de la Literatura y de las Artes en la Universidad de Valencia, solo "porque en ella había vacante en que colocarle, al perderse Cuba”. La opinión de Gaos sobre él era nefasta: llegó a visitar a D. Pedro en su casa por razones académicas, y se quedó profundamente decepcionado con la biblioteca de López y Martínez, tan paupérrima y sesgada ideológicamente:

Una vez tuve que visitarle en su casa y me recibió en su despacho y biblioteca, vi que ésta se componía de unos cuantos libros sueltos y, ocupando prácticamente todas las estanterías, que ocupaban a su vez prácticamente la pieza —cierto, reducida—, la colección, encuadernada, en gruesos volúmenes — no olviden, por Dios, que era profesor de Lógica Fundamental y de Teoría de la Literatura y de las Artes-, del Blanco y Negro $[\ldots]^{28}$

Tras las anteriores descripciones —algunas, ciertamente, demasiado expresivas_-, no obstante nos confesará que "a pesar de todo [...] persever[ó] en [su] entusiasmo por la filosofía”. Así, lo decisivo es ver que aunque durante estos años llegara a tener a cuatro profesores distintos de filosofía (M. Mayor, M. Polo y Peyrolón, J. Feo y P. M. López y Martínez), a cada cual peor —según Gaos-, sin embargo, siguió manteniendo un fuerte interés por la filosofía, sin renunciar a otros ámbitos de la cultura.

Es, por esto último, que no podemos dejar de señalar que si tenemos en cuenta los antecedentes familiares de Gaos o, al menos, aquellos de los que hemos podido tener noticia, se puede afirmar que las aptitudes ya mencionadas de los Gaos hacia la música, en particular, así como las cualidades en general

de Sevilla y luego en la Universidad de Valencia. Tal y como afirma Gaos, en la Universidad de Valencia no solo enseñaba Metafísica, sino que a partir de 1900 también enseñaba literatura griega, teoría de la literatura y de las artes y lógica.

Su doctrina filosófica era de clara orientación tomista. Gaos afirma que volvió a España "al perderse Cuba", si bien Gonzalo Díaz afirma que "no pudiendo tolerar aquel clima, regresó a la Península”. En Valencia desempeño varios cargos tales como director de publicaciones de la Juventud Católica, vicepresidente del Ateneo o secretario de la Facultad de Filosofía y Letras. Díaz Díaz, G. I99I, Hombres y Documentos de la Filosofia Española... 790-1. También puede consultarse: Proyecto Filosofía en Español: "Pedro María López Martínez (1861-1934)", en http://www.filosofia.org/ave/001/a130.htm [Consultado 11.9.10].Por esta página web hemos conocido la fecha de muerte.

${ }^{28}$ GaOs, J. I982, "Confesiones Profesionales [1953]", O. C., t. XVII... 76. De él, llega a afirmar: "no sé, ni sé que nadie supiera bien, qué materia, ni en qué lugar, ni con qué títulos" daba clases en Cuba. No sabemos en qué fecha Gaos visitó a López y Martínez, y si ni siquiera éste estaba del todo instalado en su casa. 
de la familia hacia las, si no profesiones, al menos sí vocaciones musicales y artísticas, se convertían todas en condiciones que situaban a José Gaos como un candidato potencial a inclinar su vocación hacia estas áreas relacionadas todas ellas con el arte. Creemos que en esta predisposición —además de su mala experiencia con la filosofía del bachillerato, así como ese exceso de tiempo libre que comentábamos—, si no origina, quizá sí potencia, su atención hacia la literatura.

Así pues, con relación a este punto quizá podamos asentar —en este texto- que tanto el descubrimiento de las letras con El Quijote (ya sea que nos refiramos al de 1910 o al de 1914) o al encuentro con la liberadora filosofía de Balmes hacia el verano de 1915, consolidarían definitivamente la atracción de Gaos hacia la palabra, la escritura y el pensamiento, alejándose así de un horizonte en el que sus intereses hubiesen coincidido con manifestaciones netamente artísticas, musicales o plásticas. En consecuencia, veremos a continuación cómo Gaos leyó, escribió y se formó en los distintos géneros literarios, y en distintas lenguas (español, francés y algo de alemán ${ }^{29}$ ). Para ello, sin ir más lejos, comenzaremos por el jovencísimo e improvisado grupo literario que se formará en aquellos juveniles y apasionados años (entre 1915 y 1919), y que enfocaba su atención y esfuerzos ${ }^{30}$ a todo tipo de manifestación artístico-literaria, encontrando su lugar preferido de recreo (y aprendizaje) en las siguientes cuatro publicaciones: la Revista España, la Nouvelle Revue française, el periódico El Mercantil Valenciano y el diario El Sol. Pero veámoslo por partes.

\section{LA FORMACIÓN ESTÉTICA Y LITERARIA DEL JOVEN GAOS: \\ EL GRUPo Literario de VAlencia (I9i6-igig)}

En consecuencia con lo dicho hasta ahora, es necesario hacer referencia a las muchas y fundamentales lecturas de distinta índole que el joven Gaos llevó a cabo en esos años, a modo de continuación de su autodidacta formación literaria, poética, teatral etc. Asimismo, para conocer mejor a Gaos es necesario comprender la fuerte amistad que en aquellos últimos años de su bachillerato

${ }^{29}$ Debía de tener algunas muy leves nociones de alemán, antes de 1919, pues ya en 1919 pudo leer (aprender sobre estos "primeros pliegos") el alemán, a través del libro de Historia de la filosofía de Wilhelm Windelband. GaOs, J. 2003, "[Gaos visto por sí mismo, 1942]", en O. C., t. III... 370.

${ }^{30}$ También sabemos, a ciencia cierta, que estuvo leyendo filosofía, por distintas bibliotecas valencianas (públicas y privadas). GAOs, J. 2003, “[Gaos visto por sí mismo, 1942]”, en O. C., t. III... 370. Para ampliar sobre este punto, véase nota 50 de nuestro artículo. 
previos a la universidad ${ }^{31}$ José Gaos contrajo con Max Aub y José Medina, al ser fuente valiosa de información sobre la vasta formación literaria y estética del joven Gaos. Así, por ejemplo, gracias a Max Aub disponemos de datos sobre cuáles fueron los autores que Gaos leyó en Valencia y que le influyeron en su formación durante su juventud y para siempre.

Hacia 1918, o antes, Aub, Medina, Carlos Gaos y Pepe Gaos conformaban un grupo de amigos literalmente inmerso en la cultura, la literatura e incluso el arte. José Gaos era el mayor de todos, con 16/17 años de edad;32 Carlos — su hermano, nacido en 1902 - apenas con 15 años ya "paría versos tristes, a la moda verhaereniana", ${ }^{33}$ al mismo tiempo que Max Aub, José Medina (ambos jóvenes de 14 años) y José Gaos escribían teatro — si bien sabemos que los dos últimos, solo escribieron una obra. ${ }^{34}$ Sabemos a ciencia cierta que todos estaban entusiasmados por los versos, ensayos y novelas de Ramón Pérez de Ayala. ${ }^{35}$ Sin embargo no solo leían al escritor asturiano, sino que la vasta cultura estética y literaria del grupo de amigos en aquellos días llegó a ser muy amplia y rica.

En efecto, a través de las revistas que leían con gran avidez iban adquiriendo una buena formación. Concretamente, a través de la Revista España —en palabras de Aub: "nuestra biblia" ${ }^{36}$ _, y de la Nouvelle Revue française

${ }^{31}$ Ángeles Gaos cuenta al respecto que Gaos concurría a "unas tardeadas en casa de Max Aub" —en donde aprendió... ¡ ¡ bailar!—, a las que también asistía José Medina: Gaos, Aux y Medina eran "algo así como los tres mosqueteros, [su padre] el más serio, Max el divertido y Pepe Medina el elemento moderador". GaOs, Á. 200I, "A mi padre"... 23.

32 "[José Gaos] iba uno o dos ańos por delante de nosotros; nosotros: Carlos, su hermano, José Medina Echevarría y yo". Aub, M. 200 I, "José Gaos”, en Cuerpos Presentes... 209. Recordemos que Aub y Medina habían nacido en 1903; Carlos Gaos en 1902 y José Gaos en 1900.

${ }^{33}$ Sigue diciendo Aub: "(...) a la moda verhaereniana de aquellos ańos de la primera guerra mundial, lamentándose sobre el destino de algún zapato viejo, abandonado en su charco campesino". Ibid., 210. Aub se refiere a Émile Verhaeren (1855-1916), quien fuera uno de los poetas belgas fundadores del modernismo. Hay que recordar que, asimismo, el jovencísimo Carlos Gaos también era músico aficionado — como su padre, José Gaos Berea— ya en esos años. Ibid., 215. Imaginamos que esto añadía un toque aún más melancólico y bucólico a la personalidad del joven Carlos.

${ }^{34}$ Ibid., 210. Sobre este punto, diremos algo más al final de nuestro texto.

${ }^{35}$ Según Aub, "aumentó [el] entusiasmo" sobre tal autor el hecho de que una tía de Gaos en Asturias "hubiese sido pretendida en amores por Ramón Pérez de Ayala". Ibid. En otra parte, Aub dirá que "[Pérez de] Ayala había sido novio o pretendiente". Ibid., 277.

La influencia era tal, que según Aub, el soneto que publica de Gaos Vera Yamuni en Diálogos, tiene versos "casi idénticos a otros [versos], que sabíamos de memoria, de La pata de la raposa" de Pérez de Ayala. Ibid. Según Aub, este soneto fue escrito pensado en Ángeles Gaos, su mujer. Ibid., 216.

${ }^{36} \mathrm{Ibid}$. En España leían las diferente secciones: las de "[Díez-]Canedo —letras—, a [Aldolfo] Salazar — música—, a Juan de la Encina — pintura— (...)”. Ibid., 276. Asimismo, gracias a los textos de Salazar, conocían la música de Debussy — y también debido "a la tertulia de casa de 
$($ N.R.F. $){ }^{37}$ que les leía Aub, les permitía adquirir cierta ventaja con respecto a sus contemporáneos.

Pero sus lecturas no solo se llevaron a cabo en la N.R.F. y en la revista España, sino también en el periódico El Sol, nacido algo posteriormente (el 1 de diciembre de 1917). Este período tendría un papel fundamental también en las lecturas, información y educación del joven grupo literario, en el cual, como sabemos por Aub, Pepe Gaos era parte pero, más aún, guía.

Parece claro, por lo tanto, que el grupo literario de juventud leía, y en abundancia, poesía, teatro, narrativa, etc. Estaban apasionados por la literatura en general. Completaban su formación estética a través de su conocimiento de la literatura, la historia de la música y de la pintura que la revista España traía en sus páginas. También a través de las lecturas que, en voz alta, hacía Max Aub acerca de la estética y la cultura francesas en los artículos y reportajes de la N.R.F. Por ello, no solo debemos tener en cuenta, para entender la formación literaria de Gaos sus lecturas del Quijote —recordemos: la primera, con no más de "ocho o diez años", ${ }^{38}$ y la segunda, en estos años literarios valencianos, antes de finalizar el Bachillerato, hacia $1918^{39}$ - y sus lecturas precoces para la asignatura de "Preceptiva" (especialmente, la Biblia y algo de Shakespeare), sino que, además, y tal y como decimos, debemos afirmar que Gaos continuó su formación estético-literaria, autodidacta y no reglada, a través de la prensa periódica y de revista nacionales e internacionales en aquellos años en Valencia.

Así pues, entre los años de 1916/1917 y 1919, Gaos fue un lector voraz de literatura de creación, al mismo tiempo que ávido y fiel seguidor de los estudios que sobre narrativa, ensayo, poesía, etc., ofrecía la prensa diaria. Ya hemos dicho que Gaos no solo leía asiduamente la revista España y la N.R.F., sino que también era lector fiel y riguroso, y seguramente varias veces por semana, del periódico El Sol. ${ }^{40}$ De este último diario conocemos, a ciencia cierta, que Gaos

Querol"-, así como su "iniciación en el arte moderno" en general. Aub, M. I985, "José Gaos", en Conversaciones con Buñuel (seguida de 45 entrevistas con familiares, amigos y colaboradores del cineasta aragonés), Madrid: Aguilar, 259.

${ }^{37}$ Aub, M. 200I, "José Gaos", en Cuerpos Presentes... 216. La N.R.F. fue fundada en 1909 por A. Gidé y J. Copeau, entre otros. Se trataba de una revista centrada en la Estética, la cual trataba de ser independiente en lo que refiere a temas políticos, morales o intelectuales. Cfr. http:// www.britannica.com/EBchecked/topic/420933/La-Nouvelle-Revue-francaise-NRF [Consulta: 10.01.2011]

${ }^{38}$ GaOs, J. 1999, "Carta 1", en $O$. C., t. XIX... 39. La primera lectura la hizo a través de la versión de Calleja, tal y como expusimos en una nota anterior de este trabajo.

${ }^{39} \mathrm{La}$ segunda lectura la hizo en la edición de Sopena (Barcelona). Véase Salmerón, F. 2000, Escritos sobre José Gaos, México: El Colegio de México [Colección Testimonios], 259-92. Sabemos que hacia 1923 lo volvería a leer por tercera vez —en el texto de la editorial Universal-. Sobre la relectura de 1923, véase Carta 1 (23.7.1923), en GaOs, J. I999, O. C., t. XIX... 40.

${ }^{40}$ El Sol. Diario Independiente sabemos que "era obra del ingeniero y empresario Nicolás 
leyó sistemáticamente la página de Alfonso Reyes titulada "Historia y Geografía" ${ }^{41}$ y que aparecía cada 5 o 6 días. Asimismo, en este mismo diario escribían, varias veces por semana, Unamuno, Baroja, Pérez de Ayala, Díez-Canedo, ${ }^{42}$ el propio Ortega, etc., a los cuales Gaos y sus jóvenes amigos literatos leían con fruición y regularidad ${ }^{43}$ —lo sabemos por sus propios testimonios-, cuando

María de Urgoiti (1689-1951), director de la potente empresa 'La Papelera Española'. Se consideró en su momento uno de los mejores periódicos de Europa y el mejor de Espańa”. Cfr. http:// hemerotecadigital.bne.es/. Vio la luz por primera vez el 1 de diciembre de 1917. [Consulta: 10.01.2011]

${ }^{41}$ Carta 284 [Sin fecha], en Gaos, J. I999, O. C., t. XIX... 518-20. Sobre la temprana lectura de la página de Alfonso Reyes, el propio Gaos se lo comenta a la nieta de Reyes. Esta carta que escribió Gaos a la nieta de Alfonso Reyes — si bien es cierto que solo lo podemos deducir, por un comentario que hace al final de la misma-, debió de ser enviada en 1969, antes del fallecimiento de Gaos.

La sección Historia y Geografía, era una sección fija de El Sol, y en la que escribían Alfonso Reyes y Juan Dantín Cerceda. Así, por ejemplo en el número 13, del 13 de diciembre de 1917, seguramente pudo leer una muy extensa titulada "Los centenarios", en la que Reyes reflexionaba sobre Comte - y su Calendario Positivsta —, el cardenal Cisneros y una larga reflexión sobre Lutero; o una más larga que se publicó en dos partes (1a: 27.12.1917; 2a 3.1 .1918 ), intitulada "La pasión Serbia", y en la que se reflexionaba acerca de los Balcanes. Dicha sección estimamos que aparecía, por lo que hemos consultado, con una periodicidad media de aproximadamente una semana. http://hemerotecadigital.bne.es/.[Consulta: 10.01.2011]. Nos gustaría mucho profundizar en la estancia de A. Reyes en España, muy intensa y rica, pero desgraciadamente está aquí fuera de nuestro alcance.

${ }^{42}$ Cabe mencionar que Enrique Díez-Canedo también será un exiliado desde octubre de 1938, en México, y que escribirá en Cuadernos Americanos — como posteriormente también hará un Gaos maduro-, desde el primer número (febrero de 1942) hasta su fallecimiento en junio de 1944. Jiménez León, M. 2006, "Las colaboraciones literarias de Enrique Díez-Canedo en el exilio (1938-1944)", en Escritores, Editoriales y Revistas del Exilio Republicano de 1939, Aznar Soler, M. 2006, Sevilla: Editorial Renacimiento-GEXEL, 923-9. Jiménez León elaboró su tesis doctoral sobre Enrique Diez-Canedo, critico literario (Universidad de Barcelona, Tesis Inédita, 200I). Ibid., 923, n. 1.

${ }^{43}$ Con la mera consulta de cualquier número del diario El Sol de, por ejemplo, diciembre de 1917, comprobamos cómo los textos de alguno de los autores mencionados (Unamuno, Baroja, Pérez de Ayala, Díez-Canedo u Ortega), son omnipresentes en una o dos páginas cada día. Así, hay que mencionar que, aunque no en todos los números aparece la sección de Literatura —esta se denominaba Hoja Literaria—, sin embargo sí hemos encontrado los siguientes textos que seguramente leyó Gaos: la siempre Sección doble de Ramón Pérez de Ayala titulada "Las Máscaras", donde trataba desde la obra de Wilde, además de temas políticos ("La Comedia política", 16.12.1917; "La comedia de vidas de Santos", 23.12.1917), textos de Pío Baroja, alguno de Ortega (16.12.1917: "Ideas. Otra manera de Pensar"), de Miguel de Unamuno ("Nuestro yo de los demás", 9.12.1917; "Glosas. A un pasaje del cervantino Fielding”, 16.12.1917; "Conversación”, 13.12.1917), extractos y síntesis de conferencias también de Unamuno ("La democracia y el pretorianismo. Las ideas universales y los problemas espańoles”, el 19.12.1917 en el Ateneo;), etc. Es decir: tal y como hemos comprobado, si no aparecía en El Sol la sección de Historia y Geografía escrita por Reyes, en su lugar venía una recensión sobre una conferencia de Unamuno, o bien la sección de Pérez de Ayala, etc. —cuando no la crítica diaria de libros de distintas áreas (y no solo "Artes"): Ciencias Sociales, Biología, Medicina, Arquitectura, Economía, Derecho, 
Díez-Canedo ${ }^{44}$ o Unamuno, ${ }^{45}$ publicaban, en la revista España, el primero, y en El Mercantil, el segundo. No hay razón para pensar que no hicieran lo propio cuando los mismos autores escribían en $E l$ Sol, y máxime cuando éste era además de periodicidad diaria. En estos mismos años también leyeron "todas la greguerías" ${ }^{46}$

Pero además de todas estas lecturas en la prensa, de las que, como indicábamos, hemos tenido noticia tanto por Aub, como por el propio Gaos, es necesario indicar que en estas tempranas fechas de 1917/1918 ya Gaos tenía conocimiento, a través de sus lecturas, de las ediciones de las obras clásicas de la historia de la literatura española que también Alfonso Reyes publicaba. De este no solo había leído la versión en prosa del "Poema del Cid" sino también sus ediciones y versiones, en la Editorial Calleja, de los textos del Arcipreste de Hita, Lope de Vega y Ruiz de Alarcón. Así, Gaos pudo leer muy tempranamente a Quevedo y a Gracián ${ }^{47}$ — lecturas que seguramente le encarrilarían a la concepción sobre el pensamiento hispanoamericano que como pensador, posteriormente, formularía Gaos. ${ }^{48}$

Por último, cabe mencionar que tenemos también conocimiento a través de $A u b^{49}$ de que Gaos leyó en estos años (entre 1917 y, quizá, 1920) al filósofo Lucrecio, seguramente en su poema De rerum natura, así como al español Gonzalo de Berceo por el cual, según Aub, Gaos "sentía afición". También es necesario comentar, finalmente, que gustaba de leer al poeta Francis Jammes, ${ }^{50}$ y será en estas fechas, verano de 1918, cuando Gaos disfrutará de nuevo de su pasión por la literatura, y releerá ${ }^{51}$ por segunda vez a Cervantes y su Don Quijote.

Literatura, Artes, etc. No en vano, el periódico El Sol estaba considerado uno de los mejores periódicos de España y de Europa.

${ }^{44}$ Aub, M. 200I, "José Gaos", en Cuerpos Presentes... 276

${ }^{45}$ Aub, M. 200 I, "José Gaos", en Cuerpos Presentes... 215. Unamuno, al cual afirma Aub que leían "siempre", escribía una o dos veces por semana en el periódico El Mercantil Valenciano. Cfr. Ibid. Este periódico aún sigue publicándose desde 1872.

${ }^{46}$ Aub, M. 1985, "José Gaos," en Conversaciones con Buñuel... 261. Gaos añade: “[...] todo eso se publicó en Valencia. Las primeras ediciones de estos libros de Ramón las hacía la Editorial Prometeo, cuando cambió de nombre de Sempere a Prometeo. Yo me acuerdo muy bien del tomo de las greguerías, que estaba encuadernado en una especie de encuadrillado negro y blanco. Algo así como un damero, un tablero de ajedrez". Ibid.

${ }^{47}$ Carta 284 [Sin fecha], en GaOs, J. I999, O. C., t. XIX... 518-20

${ }^{48} \mathrm{La}$ concepción del pensamiento hispanoamericano gaosiana ha sido planteada en ARÉVALO Benito, H. 2014, Entre Europa y América (II): Estudio sobre el pensamiento hispanoamericano en José Gaos, Ecuador: Universidad Técnica Particular de Loja. [Colección Humanidades, Filosofía y Teología, vol. II, 306 pp., ISBN 9789942087232.$]$

${ }^{49}$ Aub, M. 200I, "José Gaos", en Cuerpos Presentes... 219.

${ }^{50}$ Poeta francés nacido en 1868 y fallecido en 1938.

${ }^{51}$ GaOs, J. I999, "Carta 1", en O. C., t. XIX... 39. 
Asimismo, sabemos que antes de $1921^{52}$ la formación de Gaos en el ámbito estético y literario debía de ser fuertemente sólida, pues Max Aub incluso consideraba a Gaos su "maestro" ${ }_{3}$ — como hemos mencionado al comienzo de este texto-. Así, Aub no solo le consideró su maestro (y guía) en el acercamiento a la literatura sino también en lo que respecta a los autores filosóficos: para Max Aub, Gaos fue un maestro que le había dado a leer, en aquellos años anteriores a 1921, a Windelband, Taine, Renan ${ }^{54}$ y Ortega; también al francés Marcel Proust y a los españoles Ramón Goméz de la Serna, Baroja, Azorín y Unamuno. De este modo, y con relación a la filosofía, por nuestra parte quizá podamos arriesgar y apostar que si Gaos leyó realmente a Ernest Joseph Renan - tal y como afirma Aub-, seguramente lo hizo en su Souvenirs d'enfance et de jeunesse (1883), en el cual Renan cuenta cómo — según las palabras del francés - perdió "toda su confianza en esa metafísica abstracta que tiene la pretensión de ser una ciencia aparte de las otras ciencias y de resolver por sí misma los altos problemas de la humanidad", ${ }^{55}$ pues es una idea que nos parece que encaja muy bien con la mentalidad gaosiana — apotegma el cual parece guiar su posterior crítica a la metafísica. No pretendemos decir que esto substituya la influencia de Balmes —o a la lectura de posteriores filósofos—-, pero sí que se complementa bien con el pensamiento gaosiano.

\section{La CASA de las tías y PIFÓMENo}

Antes de finalizar esta pequeña incursión en la temprana formación literaria del joven Gaos, debemos, al tiempo, dejar constancia sobre algún hecho más relacionado con las mencionadas inquietudes literarias adolescentes gaosianas, pues no solo era lector de dichos temas, sino que también fue escritor (si dejamos atrás su intento de fundación de la revista Cultura en el colegio ovetense) apasionado durante esta etapa de su vida.

Es probable que Gaos repitiera un curso del bachillerato, pues, como él mismo afirma, en el verano de 1918 aún no era bachiller, y le faltaba poco para

52 Aub, M. 200 I, “José Gaos”, en Cuerpos Presentes... 219.

53 "Estudiante y amigo ejemplar [José Gaos] fue, de hecho, mi maestro (dos años de diferencia, a los 15, son largos de andar; luego el tiempo va borrándose a sí mismo; después, tan corto, ya no cuenta)". Ibid., 215. No obstante cabe señalar que Max Aub había nacido en junio de 1903 y José Gaos en diciembre de 1900 — con lo cual eran dos ańos y medio lo que se llevaban-.

${ }^{54}$ Ibid. Sobre Ernest Joseph Renan (1823-1893) sabemos que abandonó el sacerdocio al perder "la fe en el curso de su exégesis de las Sagradas Escrituras", llegando a ser "profesor de lenguas semíticas en el Collège de France de 1861 a 1863 y de 1870 hasta su muerte". Ferrater Mora, J. I979, Diccionario de Filosofía, vol. IV, Madrid: Alianza Editorial, 2841 [5ª reimpresión, 1986].

${ }^{55}$ Citado en Ibid. 
serlo. ${ }^{56} \mathrm{Si}$ esto fuese así, cabe especular que antes de iniciar sus estudios universitarios en Derecho durante el curso 1919/1920, Gaos probablemente estuvo durante el resto del curso de 1918/1919 un tanto ocioso, después de haberse presentado - y aprobado - los exámenes que no había superado durante la convocatoria oficial del curso anterior. Quizá, por ello, cabe afirmar que entre finalización del bachillerato y el comienzo de los estudios de Derecho en la Universidad de Valencia, Gaos siguiera llenando su ocio dedicándose a la autoformación literaria, o de forma solitaria o en el contexto del improvisado grupo literario valenciano que se había formado. Asimismo, también pudo llenar su tiempo con el estudio y la lectura de temas y autores filosóficos, ${ }^{57} \mathrm{y}$ al tiempo, tal y como parece, escribiendo y desarrollando esa faceta desconocida del Gaos "literato".

De hecho sabemos que el joven Gaos era muy aficionado a leer teatro y que había escrito "una tragedia en cinco actos, escrita en verso y en prosa", ${ }^{58}$ que había titulado La casa de las tías. ${ }^{59}$ Sobre esta obrita no tenemos noticia alguna más — que podamos ofrecer por nuestra parte-.

No obstante, con respecto a la narrativa y a la poesía sabemos que en diciembre de 1919 ya había escrito unas Diversiones (desaparecidas, hasta la fecha) y, hacia 1920 (y aunque se salga de los intereses de nuestro texto), algunos versos $^{60}$ los cuales, además, tenía proyectado publicar en forma de volumen. El valor de estas obras es discutible y se debe tener en cuenta que la obra literaria más significativa de Gaos no la comenzará hasta 1923: una novelita que

\footnotetext{
${ }^{56}$ Aún a riesgo de ser repetitivos, recordemos que leyó el Quijote por segunda vez (en la edición de Sopena) en el verano de 1918, siendo "por entonces bachiller, o algo menos". GaOs, J. I999, "Carta 1", en O. C., t. XIX... 39.

${ }^{57} \mathrm{Al}$ respecto, sabemos que Gaos pasó "mañanas y tardes enteras" en una biblioteca de Valencia leyendo monografías sobre autores clásicos de la filosofía. GAOS, J. 2003, "[Gaos visto por sí mismo, 1942]”, en O. C., t. III... 370. Así, sabemos que leyó Landormy, P. y Renault, M. I9I3, Filósofos griegos: Sócrates. Platón y Epicuro, Barcelona: Casa Editorial Estudio [200 pp.]; también Landormy, P.; Chartier, E.; Halbwachs, M. y Cantecor, G. i9i4, Filósofos modernos: Descartes, Spinoza, Leibniz y Kant, Barcelona: Casa Editorial Estudio [303 pp.]. El hecho de poder pasar ambas partes del día, nos hace pensar que no tenía que asistir a clases del bachillerato (pero tampoco de la Universidad). Esta situación, de ser cierta, quizá pudo darse entre el otońo de 1918 y el de 1919.

58 Salmerón, F. 2000, "Los escritos españoles de José Gaos", en Escritos sobre José Gaos... 307.
}

${ }^{59}$ Creemos que este texto que menciona Salmerón —y del que no parece conocer su títulose trata seguramente de la obra de teatro que escribió Gaos y a la que se refiere Max Aub, titulada La casa de las tías; una obra de teatro que escribió en su juventud y que "traía a las tablas [del escenario] no sé qué sucesos familiares asturianos, de casas de sus abuelos, donde pasó su niñez". Aub, M. 200 I, Cuerpos Presentes... 210. En nuestra opinión, creemos que sería de alto interés encontrarlo —si existiese todavía alguna versión-. De ser así, su lectura desvelaría algunos secretos acerca de la personalidad y el perfil psicológico y la formación de nuestro Gaos. Sobre esta cuestión ha escrito excelentemente el profesor A. Zirión, como señalamos en siguiente nota.

${ }^{60}$ Carta 1, en Gaos, J. I999, O. C., t. XIX... 41. 
redactaba y que llamó Pifónemo. ${ }^{61}$ Pifómeno, el protagonista, en el fondo es el propio Gaos. Quizá con la elección del nombre (en realidad: Epifenómeno, que es término propio de la Psicología y de la Filosofía: "Fenómeno accesorio que acompaña al fenómeno principal y que no tiene influencia sobre él"'62), Gaos pretendía hacer relación a su frustración como potencial estudiante de Filología Clásica — como se dirá un poco más abajo—o Filosofía. En cualquier caso, lo que sí podía insinuar semejante título eran algunas inquietudes, literarias y filosóficas, las cuales podía sentir Gaos como propias. Sabemos que Pifónemo era una novela autobiográfica: esto no es una suposición nuestra, sino que es el propio Gaos quien lo afirma cuando narra en ella cómo un padre no permite estudiar a su hijo la carrera de Filosofía:

\section{[...] artificio por lo demás tomado a la realidad de mi vida ${ }^{63}$}

El propio Gaos, al contárselo a su amigo de juventud, Antonio Moxó, lo confesará de forma más directa:

[en ella quise] concentrar en el espacio de la novela, mi experiencia desde los catorce años hasta la actualidad $[=1924]^{64}$

Lamentablemente no han llegado hasta nosotros todos los versos, ${ }^{65} \mathrm{ni}$ la obra de teatro ni la novelita. Sin embargo, creemos que estas creaciones literarias, y a pesar de estar hechas entre la pubertad y la juventud, son claro síntoma de que fue en estos años cuando Gaos consolidó, de manera perenne,

${ }^{61}$ Conocemos la existencia de Pifónemo por una carta de Gaos a su amigo Antonio Moxó, escrita el 6 de agosto (1923): "Ayer precisamente concreté por escrito su pensamiento capital y original”. Carta 2 (7.8.[1923]), en Gaos, J. I999, O. C., t. XIX... 42-6, 44. Desgraciadamente, no ha llegado hasta nosotros su texto. No obstante, podemos conocer parte de su contenido por las Cartas 2, 5 y 8 de la correspondencia de Gaos con Moxó. Este tema lo ha tratado, más allá de lo que mencionamos aquí y con la exquisitez a la que nos tiene acostumbrados, el profesor Antonio Zirión Q.: Zirión, A. 20I3, "Filosofía vs. Vida en José Gaos. Introducción de la problemática sobre la base de Pifónemo", en Filosofía y vida: debate sobre José Gaos, S. Sevilla y M. VÁzQuez (eds.), Madrid: Biblioteca Nueva, 23-40.

${ }^{62}$ Diccionario de la Lengua Española de la RAE, t. V, Madrid: Espasa, 200 I, 637.

${ }^{63}$ Esto nos hace pensar que la novela Pifónemo nos hubiera facilitado quizá algunos datos biográficos relevantes para comprender mejor la vida - y seguramente, el pensamiento- del joven Gaos. Carta 1, en GaOs, J. I999, O. C., t. XIX... 41. En ella, seguramente también hablaría de la relación conflictiva con su padre y que mencionaba su amigo Max Aub en su libro "Cuerpos presentes".

${ }^{64}$ Ibid. La Carta 1 está escrita en 1924.

${ }^{65}$ Salmerón, F. 2000, "Los escritos españoles de José Gaos", en Escritos sobre José Gaos... 308. Los poemas, según parece, se perdieron todos, aunque afirma Salmeron que: "ya cercano a cumplir los sesenta ańos de edad — nos cuenta Vera Yamuni—, cuando Gaos volvió a escribir 
una adoración por la literatura — en cualquiera de sus formas — que le acompañaría a lo largo de su vida. De hecho, creemos que es justo en estas fechas cuando Gaos se llegó a plantear seriamente hacer estudios de Filología Clásica, pues tenía gran interés por ésta —afirma— incluso prefiriéndola "antes que a la Filosofía":

La latría de Grecia no podía menos de tenerla: cómo a la tan generalizada no iba a ceder de mozo; hasta dudé en algún momento si dedicarme a la Filología Clásica antes que a la Filosofía ${ }^{66}$

Sea como fuere, desconocemos las razones que le impidieron estudiar "Clásicas". Si elucubramos —eso sí-, podemos anticipar que pudo deberse a, seguramente, de nuevo las tensiones paternas dentro del núcleo familiar, pues si la filosofía no estaba bien considerada, quizá tampoco lo estuviera la Filología Clásica. Lo que sí conocemos es cómo el joven Gaos comenzará, por su cuenta y riesgo, el estudio de la filosofía que complementará con el de la Literatura, tal y como hemos intentado mostrar en este breve escrito.

\section{Conclusiones}

Así, tal y como venimos diciendo - y gracias a diversos testimonios de amigos de Gaos de la juventud, que hemos visto-, una de las principales características de la formación que hacia 1919 — y desde, al menos, 1915— se estaba procurando nuestro joven Gaos consistía en que su formación e intereses aglutinaban áreas en apariencia muy dispares: literatura, teatro, poesía, filosofía, e incluso novela policíaca, ${ }^{67}$ etc. Ya hemos mencionado cómo este

poemas que nunca quiso publicar, y a traducir poesía de otros idiomas para colmar sus horas de descanso y soledad, gustaba recordar algunos de los escritos durante su juventud (...) Vera recogió tres sonetos". Estos tres sonetos se pueden ver en el libro de Yamuni titulado José Gaos. El hombre y su pensamiento, Facultad de Filosofía y Letras, UNAM, México, 1980.

${ }^{66}$ Gaos, J. 1982, "Confesiones Profesionales [1953]", O. C., t. XVII... 66. No está de más recordar aquí que la palabra "latría" procede del griego $\lambda \alpha \tau \varrho \varepsilon ı \alpha$, "adoración". El diccionario de la RAE lo define como "Reverencia, culto y adoración que solo se debe a Dios". Cfr. RAE, t. VI, 200 I, 917.

${ }^{67}$ Sobre este punto, no hemos mencionado nada, porque no podemos conocer qué novelas debió de leer exactamente (ni la influencia que pudo tener en el joven Gaos); como máximo deducir alguna contextualización (qué más bien nos da muestras de cómo podría ser el acceso a la cultura para un joven acomodado de principios del siglo xx en Valencia): pues solo sabemos que para la mencionada Revista Cultura, Gaos escribió el primer capítulo de unas (así las tituló) Aventuras de Ninchi Micurcia, una "parodia de novelas de detectives y ladrones", imitando a los personajes de "Sherlock Holmes, Nick Carter, Nat Pinckerton... [o] Raffles...", las cuales le sirvieron para completar el primer número de la Revista Cultura. GAOS, J. 2003, "[Gaos visto 
aspecto de su educación es fundamental para comprender el estilo de pensamiento que Gaos adquiriría con el tiempo. No obstante, cabe señalar que Martínez Bisbal ya planteó en 2008 que Gaos barajaba a sus escasos 23 años presentarse "al Premio Nacional de Literatura con un ensayo sobre el Quijote", ${ }^{68}$ pero, al tiempo, nos deja un sabor agridulce cuando parece que Gaos plantea su "despedida de la literatura como profesión", si bien queda claro, para Martínez Bisbal, que sin embargo, Gaos, aún "mantiene todavía su vena literaria, ahora integrada en la profesión filosófica”. Al respecto, nos dice el propio Gaos ${ }^{69}$ :

Ahora bien, si llegara a ser, allá tras la madurez de la vida, el Filósofo, me gustaría poder condensar mi concepción del mundo y mi sentimiento de la vida en una obra más amplia, más universal, más humana, que la puramente de ciencia, y recoger en ella entonces todas las experiencias vitales y artísticas de estos mis principios literarios, como el Pifómeno — que usted recuerda ${ }^{70}$

Así pues, en esta época que estamos describiendo, y tal y como manifestaron sus inquietudes y proyectos de la época de estudiante en el colegio dominico ovetense - con la creación (interrumpida) de la revista Cultura, así como con la profunda amistad literaria que le unía a su hermano Carlos y a sus amigos Aub y Medina en torno a gustos y lecturas compartidas-, podemos afirmar que tanto sus intereses como su formación literaria estaba en estos años asentándose de forma firme y duradera. Como consecuencia de toda esta formación y en honda relación con el aprendizaje sobre la literatura que Gaos iba alimentando poco a poco, no solo sus lecturas sino también sus creaciones literarias fueron muy variadas y tuvieron un amplio marco de desarrollo, influencia la cual se aprecia en sus posterior visión acerca del pensamiento hispanoamericano, así como en su lectura constante, a través del tiempo, de obras literarias — tal y como se desprende durante la lectura de

por sí mismo, 1942]”, en $O$. C., t. III... 367. Cabe añadir que, excepto esta noticia, no poseemos ninguna otra información sobre la continuación de estas Aventuras... escritas por Gaos, si bien también se podría rastrear en las obras de Nick Carter (en realidad, un grupo colectivo de autores, y cuyas primeras obras llegaron de Norteamérica a España hacia 1911; se publicaron 63 novelas, cortas o largas, y lo hizo la editorial Sopena. Cfr. Colmeiro, F. I994, La novela policiaca española: teoría e historia crítica, Barcelona: Anthropos, 100); así como las obras de Pinckerton o Raffles y especular con qué títulos existían, cuáles pudieron ser de interés para Gaos, etc. — $\mathrm{si}$ bien, estas lecturas no parece que fueran más allá de un mero entretenimiento para un joven, culto y con posibles, de aquella época-.

${ }^{68}$ Martínez Bisbal, J. 2008, "Vocación filosófica y crisis (dos apuntes)", Visiones sobre un transterrado. Afán de saber acerca de José Gaos, S. SEvilla (ed.), Madrid/Frankfurt: Iberoamericana/Vervuert, 211-37, 231.

${ }^{69} \mathrm{Ibid} ., 235$.

${ }^{70}$ Carta a su amigo Moxó, del día 28.10.1927, en GaOs, J. I999, O. C., t. XIX, 123-7. Cfr. Ibid. 
toda su correspondencia publicada, incluso, llegando a los años 50 del pasado siglo $^{71}$. De esta manera, no nos parece que Gaos abandonara nunca la literatura de manera definitiva, sino que, más bien, la integró en su concepción de en qué consista el "pensamiento hispanoamericano": nuestro tipo de pensar como hispanoamericanos, para José Gaos, se puede definir como un modo de hacer filosofía cuya existencia (y desde los orígenes de su historia) ya había sido anunciada por Wilhelm Dilthey ${ }^{72}$ que recorrer todas las formas escritas de expresión (de la religión a la filosofía, pasando por la poesía) y que ahora recogería Gaos al explicar éste el sentido de nuestra tradición: se trata de una manera de hacer filosofía ametafísica y ametódica en la cual "el pensador hispano-americano contemporáneo se 'produciría', mediante la palabra oral, mejor, más a su gusto. Mediante ella, discurriría, descubriría, si no exclusiva, más fácilmente, y sobre todo, más a su satisfacción". ${ }^{73}$ Estas formas, y a pesar de su carácter oral, serían recogidas en las formas escritas preferidas por el pensador "hispanoamericano": el ensayo, las cartas, el artículo de revista general y de periódico. Este modo en que queda recogido nuestro pensamiento implica que preferimos las formas literarias, ensayísticas y epistolares de expresión. Al mismo tiempo, señala Gaos que todo texto puramente literario (es decir, de ficción) presente en nuestro pensar como hispanoamericanos, es tendente a preocuparse por temas ético-morales, políticos y pedagógicos.

En definitiva, el escritor-pensador hispanoamericano tiene un modo especifico de producción, y es de bien escribir. Existe, pues, una aproximación a la literatura si atendemos a la forma en que expresamos los contenidos más netamente filosóficos de nuestro pensamiento. Así, dirá Gaos que los pensadores hispanoamericanos escriben como ensayistas: en España (Feijoo, Cadalso,

${ }^{71}$ En el mencionado epistolario, pueden verse referencias a la literatura durante todas las épocas de su correspondencia; pero nos llama la atención que, sin embargo, a partir de los años 50 siga haciendo bastantes (y diversas) referencias a obras literarias (Cfr. Ibid., 315-475).

${ }^{72}$ Dilthey afirmó que "la compleja relación que se abre [...] entre religión, filosofía, experiencia de la vida y poesía, nos obliga a remontarnos a las relaciones que dominan entre estas fuerzas de la cultura en cada individuo y en la sociedad". Cfr. Dinthey, W. i944, La esencia de la filosofía, Buenos Aires: Biblioteca Filosófica, 130 [205 pp.]. Tenemos noticia, además, de que Gaos ya en el verano de 1933 conocía la filosofía de Dilthey, pues era parte de la primera conferencia del ciclo de cuatro que impartió bajo el título general de "La filosofía en el Siglo xx". Cfr. GaOs, J. I935, "La filosofía en el Siglo xx" en La Universidad Internacional de Verano en Santander. Resumen de sus trabajos (1933-1934), MiNISTERIO DE INSTRUCCIÓN PÚbLICA Y BELLAS ARTES, "Decreto de la Fundación de la Universidad Internacional", Madrid: Ministerio de Instrucción Pública y Bellas Artes (Patronato de la Universidad Internacional de Verano en Santander), 151-61, 152.

${ }^{73}$ Gaos, J. 1993, O. C., t. V, El pensamiento hispanoamericano. Antología del pensamiento de lengua española en la edad contemporánea, México: UNAM, 63 [Prólogo de Elsa Cecilia Frost]. Cursiva nuestra. 
Larra, Valera, Ganivet, Unamuno, la generación del 98, Ortega, Ayala...) y en América (Sarmiento, Montalvo, Martí, Rodó, Prada, Ureña, Reyes, Varona, Romero). Pero también los autores de literatura de ficción escriben como pensadores, dándose siempre desde la literatura un acercamiento a los problemas filosóficos ${ }^{74}$ al hacer referencia al espiritu ideológico que ha existido a lo largo de los siglos en la Literatura hispanoamericana: desde a) el "término del triple movimiento místico, escolástico y renacentista” que es propio y característico del pensar hispano-americano; b), el "siglo de Oro"; c) continuando por el "prosaico" siglo Xviı en España; d) en "los dos pensadores más importantes" — desde "el movimiento místico", afirma—: Miguel de Unamuno, José Ortega y Gasset; e) en "novelistas" como Pío Baroja y Ramón Pérez de Ayala; f) en "poetas" como Antonio Machado y Juan Ramón Jiménez; g) y en último lugar, en los seis "nombres centrales" de la literatura hispanoamericana según Henríquez Ureña: "Bello, Sarmiento, Montalvo, Martí, Darío y Rodó”. En este punto, vemos que muchos de los nombres que Gaos aquí propone caerían, al mismo tiempo, en varias "categorías"; pero, sea como fuere, vemos cómo para Gaos hay un camino entre filosofía y literatura (o viceversa), el cual recorre el pensamiento hispanoamericano desde la Edad Moderna hasta la Contemporánea.

Asimismo, afirma que incluso existe un género intermedio entre ambos - literatura de ideas y literatura de imaginación ${ }^{75}$-, representado por: Sarmiento, Macedonio Fernández, Ortega, Lizardi y "algo de" Ganivet, Unamuno, Vasconcelos, Montalvo y Martí.

Sea como fuere, Gaos piensa que todos los autores mencionados tienen algo en común, pues los tres tipos mencionados de "pensamiento hispanoamericano" (usemos las denominaciones gaosianas: literatura de ideas, literatura de imaginación y literatura "entre límites") poseen una forma ideativo-imaginativa de producir pensamiento: se trata de un pensamiento no cientificista, que se expresa de manera muy peculiar con las siguientes formas:

[...] el ensayo y el artículo de revista general y de periódico; el libro de génesis, estructura y calidades, valores, reducibles a los del ensayo. Que no es el libro integrado con ensayos y artículos publicados o no anteriormente $[\ldots]^{76}$

E incluso...

${ }^{74}$ Ibid., 69 y 70.

${ }^{75}$ Gaos, J. I993, O. C., t. VI, Pensamiento de Lengua Española... 60.

${ }^{76}$ Ibid., 60ss. 
[...] en la palabra oral desatada en el correr seguido o en el saltar sobre los obstáculos de la interlocución $[\ldots]^{77}$

Pues es el nuestro un pensamiento que discurre:

[...] por conceptuación y hasta discurso mediante imágenes, por términos del habla corriente o de un estilo literario tomados en acepciones "contextuales", "ocasionales" o "circunstanciales" que los hinch[an] [=a los términos] de una significación o intención ideológica más amplia o más densa, menos o más nueva o única en cada contexto, ocasión o circunstancia, entre las cuales encuentra, pues, contradicción la inteligencia que, procediendo tradicionalmente, las toma abstractas de estos contextos, ocasiones o circunstancias que la concretan ${ }^{78}$

En consecuencia, con este artículo hemos querido orientar nuestro interés a preguntarnos —e invitar a que nos preguntemos — cuál fue la influencia de la literatura en el pensamiento del joven Gaos, para lo cual consideramos que es necesario conocer mejor toda su formación estético-literaria durante su adolescencia (especialmente, de sus lecturas literarias, pero también de toda esta etapa valenciana de juventud, en la cual Gaos leyó numerosos artículos de periódico en la prensa de la época, la cual hemos citado e invitamos, desde aquí, a su trabajo sistemático ${ }^{79}$ ), y de cara a comprender así algunos matices del pensamiento del Gaos maduro: ya que esta formación estético-literaria no solo sería el pilar fundamental del satisfactorio desempeño de lo que, posteriormente, sería su trabajo como Lector de Lengua y Literatura Espańolas en Montpellier (Francia) durante un curso académico (el de 1924/1925; formación literaria reconocida y refrendada, seguramente, por Morente como muy valiosa y que pudo valerle que se le confiara el puesto mencionado en Francia desde el Centro de Estudios Históricos), sino que todo parece apuntar a que, asimismo, la mencionada excelente educación literaria, junto a la filosófica — por no mencionar el consabido lugar común de las clases de filosofía y literatura que Gaos, durante su época madrileña en la Facultad de Filosofía y

77 Ibid., 64.

${ }^{78}$ Ibid., cursiva nuestra.

${ }^{79}$ Modestamente, proponemos que este tema podría dar de sí para una tesis doctoral (o, al menos, para una tesina), pues la información que aparece en los archivos digitalizados de la BNE es ingente, y la lectura por parte de Gaos de los textos de Reyes, Unamuno, Ortega, etc., así como los de estética, podría darnos una mejor idea de qué pudo conocer Gaos (junto con Aub, etc.) en dichos artículos, que eran auténticos manifiestos de filosofía, arte, ciencia, política, etc., además de estar escritos en una prosa excelente y de gran calidad. Así, véase: http://hemerotecadigital.bne.es/details.vm?q=id:0000182002\&lang=es, donde se dice (de tan solo el periódico $E l$ Sol) que hay más de "5.969 ejemplares" [Consultado: 12.01.2013]. 
Letras, impartía junto con Montesinos y a las que, al parecer, asistió alguna vez el propio Ortega-, le orientarían a formular su propuesta acerca de la común trayectoria literaria y filosófica de los contenidos, autores y temas del pensamiento hispanoamericano de lengua española. 


\section{BiBLIOGRAFÍA}

Abellán, J. L. I99i, "La Escuela de Madrid: José Gaos y la proyección americana del orteguismo", en Historia critica del pensamiento español. Tomo 5 (III). La crisis contemporánea. De la gran guerra a la guerra civil española (1914-1939), en J. L. Abellán, Madrid: Espasa Calpe.

Abellán, J. L. 200 i, "Los Gaos: una saga familiar eminente”, en En torno a José Gaos, T. Rodríguez de LeceA (ed.), Valencia: Institució Alfons el MagnànimDiputació de València [Colección Pensamiento y Sociedad].

Arévalo Benito, H. 20 I 4, Entre Europa y América (II): Estudio sobre el pensamiento hispanoamericano en José Gaos, Ecuador: Universidad Técnica Particular de Loja. [Colección Humanidades, Filosofía y Teología, vol. II, 306 pp., ISBN 9789942087232. Dir. colección: Héctor Arévalo]

Aub, M. 1985, "José Gaos", en Conversaciones con Buñuel (seguida de 45 entrevistas con familiares, amigos y colaboradores del cineasta aragonés), Madrid: Aguilar.

Aub, M. 200I, “José Gaos”, en Cuerpos Presentes, Valencia: Fundación Max Aub. [Ed., introd. y notas de José-Carlos Mainer]

Delgado de la Rosa, J. A. 20io, Libertad de Conciencia y Derechos Humanos. Vida y Pensamiento de José María Diez-Alegría, Madrid: Universidad Carlos III de Madrid. [Colección Religión y Derechos Humanos. Dir. colección: J. J. Tamayo]

Díaz Díaz, G. I99I, Hombres y Documentos de la Filosofía Española, t. IV, H-LL, Madrid: Consejo Superior de Investigaciones Científicas/Centro de Estudios Históricos.

Díaz Díaz, G. I998, Hombres y Documentos de la Filosofía Española, t. V, M-N-Ñ, Madrid: Consejo Superior de Investigaciones Científicas/Centro de Estudios Históricos.

Díaz Díaz, G. I998, Hombres y Documentos de la Filosofía Española, t. VI, O-R, Madrid: Consejo Superior de Investigaciones Científicas/Centro de Estudios Históricos.

Espinosa, A. I999, "Cronología y bibliografía de José Gaos", en Homenaje a José Gaos, AA.VV., México: FCE/La Gaceta del Fondo de Cultura Económica. [Nueva Época: no 348. Diciembre (Coord.: Alberto Espinosa), 62 pp.]

Ferrater Mora, J. I979, Diccionario de Filosofía, vol. II, Madrid: Alianza Editorial. [5ª reimpresión, I986]

Ferrater Mora, J. I979, Diccionario de Filosofía, vol. IV, Madrid: Alianza Editorial. [5ª reimpresión, I986]

Gaos, A. 200 I, "A mi padre”, en En torno a José Gaos, T. Rodríguez De LeceA (ed.), Valencia: Institució Alfons el Magnànim-Diputació de València, 21-49 [Colección Pensamiento y Sociedad]. 
GaOs, J. I935, "La filosofía en el Siglo xx" en La Universidad Internacional de Verano en Santander. Resumen de sus trabajos (1933-1934), MINISTERIO DE Instrucción Pública Y Bellas ARtes, "Decreto de la Fundación de la Universidad Internacional”, Madrid: Ministerio de Instrucción Pública y Bellas Artes (Patronato de la Universidad Internacional de Verano en Santander). [390 pp.]

Gaos, J. I982, "Confesiones Profesionales [1953]", en O. C., t. XVII, Confesiones Profesionales. Aforística, México: UNAM, 43-137. [Prólogo y selección de la Aforística: Vera Yamuni Tabush. Coordinador: Fernando Salmerón]

GaOs, J. I993, O. C., t. V, El pensamiento hispanoamericano. Antología del pensamiento de lengua española en la edad contemporánea, México: UNAM. [Prólogo de Elsa Cecilia Frost]

Gaos, J. I999, O. C., t. XIX. Epistolario y Papeles Privados, México: UNAM. [Edición, prólogo y notas de Alfonso Rangel Guerra. Coordinador: Antonio Zirión Q.]

GaOs, J. 2003, “[Gaos visto por sí mismo, 1942]”, en O. C., t. III, Ideas de la Filosofía (1938-1950), J. Gaos, México: UNAM, 359-435. [Prólogo de Abelardo Villegas. Introducción de Antonio Zirión Q.]

GaOs, J. 2007, "Las ciencias teóricas y las ciencias normativas según Husserl", en Filósofos españoles en la Revista de Pedagogía (1922-1936), A. Casado y J. Sánchez-Gey (eds.), Santa Cruz de Tenerife/Las Palmas de Gran Canaria: Ediciones Idea.

Landormy, P. y Renault, M. I913, Filósofos griegos: Sócrates. Platón y Epicuro, Barcelona: Casa Editorial Estudio. [200 pp.]

Landormy, P.; Chartier, E.; Halbwachs, M. y Cantecor, G. i9i4, Filósofos modernos: Descartes, Spinoza, Leibniz y Kant, Barcelona: Casa Editorial Estudio. [303 pp.]

López García, M. 2007, "José Gaos y la filosofía coetánea," Eikasia. Revista de Filosofía, Año II, 9: 91-187.

López Moreno, Á. I990, “Comprensión” " "Interpretación” en las ciencias del espiritu: W. Dilthey, Murcia: Universidad de Murcia. [Secretariado de Publicaciones e Intercambio Científico, Colección Maior no 41]

Martínez Bisbal, J. 2008, "Vocación filosófica y crisis (dos apuntes)", en Visiones sobre un transterrado. Afán de saber acerca de José Gaos, S. SEvilla (ed.), Ma$\mathrm{drid} /$ Frankfurt: Iberoamericana/Vervuert, 211-37.

Mindán, M. 200 I, "El magisterio de José Gaos en España”, en En torno a José Gaos, T. Rodríguez de LeceA (ed.), Valencia: Institució Alfons el MagnànimDiputació de València, 51-68. [Colección Pensamiento y Sociedad]

MorA, J. L. 20 I4, "María Zambrano: Cervantes y la reforma del entendimiento español”, eHumanista, vol 3: 661-674. [Volumen dedicado a Cervantes. 
http://www.ehumanista.ucsb.edu/Cervantes/volume\%203/pdf/ehumcerv3. mora.pdf (Consulta: 2.1.2015)]

NúŃEz Ruíz, D. 2006, "Reforma y modernización de la universidad española en el gozne de los siglos xIx y xx”, Revista de Hispanismo Filosófico, 11: 111-23.

Salmerón, F. 2000, Escritos sobre José Gaos, México: El Colegio de México. [Colección Testimonios]

Sevilla, S. y Vázquez, F. 2013, Filosofía y Vida. Debate sobre José Gaos, Madrid: Editorial S. XXI. [Colección: "Pensar en Español"]

Windelband, W. I900, Geschichte der Philosophie, Tübingen/Leipzig: Verlag von J.C.B. Mohr (Paul Siebeck).

Zirión, A. 20I3, "Filosofía vs. Vida en José Gaos. Introducción de la problemática sobre la base de Pifónemo", en Filosofia y vida: debate sobre José Gaos, S. Sevilla y M. Vázquez (eds.), Madrid: Biblioteca Nueva, 23-40. 